\title{
Exploring the Determinants of IoT Adoption: Findings from a Systematic Literature Review
}

\author{
Marian Carcary $^{1}$, Giovanni Maccani ${ }^{1}$, Eileen Doherty ${ }^{1}$, Gerard Conway ${ }^{1}$ \\ ${ }^{1}$ Maynooth University, Innovation Value Institute, Co. Kildare, Ireland \\ \{marian.carcary, giovanni.maccani eileen.doherty, \\ gerard.conway\}@mu.ie
}

\begin{abstract}
.
The Internet of Things (IoT) heralds a new era of disruptive technologies that provide organizations with both benefits and challenges. However, organizational adoption of IoT is not yet widespread and greater understanding of the phenomenon is required. This study examines the existing literature on the key determinants (drivers, benefits, barriers, and challenges) that influence the adoption of IoT by organizations. Therefore, this paper presents findings from a Systematic Literature Review (SLR) and concept matrix approach to identify these IoT adoption determinants at the organizational level. The key constructs of the Unified Theory of Acceptance and Use of Technology (UTAUT) were examined in relation to the determinants identified to understand applicability of this theory in the IoT context. Future research will complement these findings through an empirical investigation. Therefore, the overall aim of this research is 1) to generate a model that outlines the determinants influencing organizational IoT adoption and 2) to ascertain the applicability of UTAUT in understanding IoT adoption and to further enrich UTAUT by contextualizing its constructs to the IoT phenomenon.
\end{abstract}

Keywords: Internet if Things (IoT), IoT adoption determinants, IoT drivers, IoT benefits, IoT barriers, IoT challenges, systematic literature review, concept matrix, Unified Theory of Acceptance and Use of Technology (UTAUT)

\section{Introduction}

The Internet of Things (IoT) paradigm represents a nascent concept that heralds a new era of disruptive technologies, enabling ubiquitous, unbounded connectivity of different types of devices and pervasive computing scenarios [12, 14]. It is the next revolutionary concept in the transformation of the Internet into a fully integrated network, enabling a harmonious interaction between societies, individuals, and smart things [29]. 
IoT is defined as a network of intelligent heterogeneous physical devices or objects that contain embedded technology and are seamlessly interconnected [2, 43]. These devices are augmented with sensing, computing, and communication capabilities, enabling them to communicate and sense or interact with their internal states or external environments [14]. They are connected to form a network, across which data can be transferred without human-to-computer or human-to-human interactions [71]. By leveraging insights from the collective analyses of this data, organizations can solve real-world problems and deliver reality-augmented services and functionalities that were not heretofore imagined $[7,53]$. These functionalities have the potential of disrupting multiple application areas across both the private and public sectors including supply chain management [49], manufacturing [30], healthcare [42], and traffic management in cities [39]. This study focuses on IoT from an end-to-end perspective where IoT can be conceptualized as a complex 'system of systems' that is comprised of three high level layers. These include: a 'Devices' layer where objects are augmented with sensing and data identification and capture technologies; a 'Network' layer across which data is transferred to local processing technologies where it is collected, filtered, and aggregated; and a 'Data Storage and Analytics' layer, where the data can be leveraged to generate new analysis and insights that deliver business value [36].

IoT is anticipated to have a greater impact than the Internet itself [63], as by 2020 it is projected that the number of Internet-enabled connected devices will reach 50 billion [23]. The economic impact of IoT has been forecast to have a total value of between \$3.9 and \$11.1 trillion per year up to 2025 [41]. However, organizational adoption of IoT is far from being universal. In a 2014 survey of 1400 C-suite executives, 73\% had not made any concrete IoT investments, and only $7 \%$ had developed a comprehensive IoT strategy [1]. A 2015 survey of more than 200 IT and business leaders revealed that $42 \%$ were only starting to consider the potential impact of IoT on their business [69]. In a further 2016 survey of over 500 business executives, 90\% of organizations remained in the IoT planning or proof of concept stages, with only $20 \%$ expecting to implement IoT solutions at scale by 2020 [11].

While it is anticipated that the momentum to adopt IoT will rapidly grow due to competitive pressures on organizations to transform [40], the lack of IoT adoption by organizations to date may be partly explained by the fact that it is very different from the adoption of other technologies [9]. This is because IoT requires the adoption of an ensemble of hardware (e.g. sensors, IoT gateways, cloud infrastructure), software (across the various IoT layers), and networking technologies that are supplied by multiple vendors. As a consequence, the IoT landscape reflects a rich variety of protocols, technologies, and devices [51] that have different requirements, boundary conditions, traffic characteristics, and involve multiple stakeholders [7, 21]. In addition, there is a scarcity of studies in relation to the social, behavioral, economic, and managerial issues 
associated with IoT, thereby hampering an organization's ability to make informed decisions about IoT adoption and use [40]. Given the assertion that IoT adoption is different from that of other technologies, it raises the question as to whether existing IS theories of technology adoption are sufficient to provide the basis for an effective understanding of the IoT phenomenon. IS research acknowledges the need to investigate "How will theories of IT adoption and diffusion develop to take account of IoT?" (see call for papers for the Journal of Strategic Information Systems Special Issue on "IT Governance on the Internet of Things”, October 2017 - https://www.journals.elsevier.com/the-journal-of-strategic-information-systems/call-for-papers). Consequently, the research question explored in this study is 'what are the determinants that influence the adoption of IoT by organizations'? This question is addressed in two sequential phases. Phase 1 (discussed in this paper) identifies the current understanding in the literature of the key determinants of IoT adoption by undertaking a systematic literature review of IoT adoption drivers, benefits, barriers, and challenges, and a content analysis of the relevant literature. Through developing a concept matrix [76], the identified themes are categorized within the constructs of the Unified Theory of Acceptance and Use of Technology (UTAUT) [73]. Thus, this paper contributes through a systematic analysis of the extant literature on IoT adoption through the lens of the UTAUT theory. These findings allow reflecting on the current understanding of IoT adoption and representing the foundation for future empirical research avenues. Hence, Phase 2 of this study (discussed in a future paper) will complement these findings through an empirical investigation. Therefore, the overall aim of this research is to 1 ) generate a model that outlines the determinants influencing IoT adoption by organizations and 2) ascertain the applicability of UTAUT in understanding IoT adoption and to further enrich UTAUT by contextualizing its constructs to the IoT phenomenon.

\section{Theoretical Background}

Research in the area of adoption, diffusion, and acceptance of technologies is argued to be a mature field in the IS literature [34, 44, 78]. Several theoretical frameworks have been formulated across disciplines to study these phenomena. Venkatesh et al, (2003) propose a "Unified Theory of Acceptance and Use of Technology" (UTAUT) that integrates eight widely used theories: (1) Theory of Reasoned Action [25], (2) Technology Acceptance Model (TAM) [19] and its extension [72], (3) Motivational Model [20], (4) Theory of Planned Behavior (TPB) [3], (5) Combined TAM and TPB model [68], (6) Model of PC Utilization [70], (7) Diffusion of Innovations Theory [55], and (8) Social Cognitive Theory [17]. For this study, UTAUT was selected as the underpinning theoretical framework to map and interpret the determinants of IoT adoption for the following reasons. Firstly, UTAUT synthesizes 
many alternative views on IS adoption in the literature and provides a common structure to harmonize the constructs of different theories, many of which were similar in nature. More importantly, UTAUT addresses a fundamental limitation of the models that underpin it, in that they are focused on "individual-oriented information technologies as opposed to more complex and sophisticated" [73, p.427] ones. IoT clearly represents a complex and sophisticated technology that falls consistently within the scope of UTAUT. Since its inception, UTAUT has been widely employed as a theoretical lens for studies associated with individual and organizational IS adoption and use, with reference made to a wide range of technologies, including those that are more complex and specialized in nature. Examples of such sophisticated technologies within organizations include biometrics authentication systems [5], customer relationship management systems [48], e-government services [4], electronic HRM [32], electronic medical record systems [15], electronic procurement systems [62], and enterprise resource planning systems [35].

This paper considers the four constructs defined within UTAUT as determinants of IS adoption: Performance Expectancy, Effort Expectancy, Social Influence, and Facilitating Conditions [73]. An overview of these constructs is provided below, and they are used in subsequent sections as the basis for theoretically framing the IoT adoption determinants systematically identified in the literature. Performance Expectancy is defined as the "degree to which an individual believes that using the system will help him or her to attain gains in job performance" [73, p.447]. The underlying assumption is that behaviors are influenced by the value outcomes anticipated from using a technology. Effort Expectancy is the "degree of ease associated with the use of the system" [73, p.450]. This construct infers that when institutionalizing a new technology, behaviors are influenced by the degree of effort required to process complex new stimuli. Social Influence is "the degree to which an individual perceives that 'important others' believe he or she should use the new system" [73, p. 451]. This implies that behaviors are influenced by how people believe others will view them as a result of using a technology. Facilitating Conditions are described as "the degree to which an individual believes that organizational and technical infrastructure exists to support use of the system" [73, p.453]. The underlying position is that aspects of the technological and organizational environment can lower the barriers for using atechnology.

\section{Systematic Literature Review (SLR): The Approach}

In order to better understand the IoT phenomenon, the approach of this study involved a concept-centric examination of drivers, benefits, barriers, and challenges to 
IoT adoption in organizations. These key determinants were identified through understanding the requirements for effectively conducting a literature review $[50,58]$ and following a systematic literature review (SLR) approach [47], and were analyzed using a concept matrix [76]. The SLR adhered to the 8 steps proposed by Okoli (2015) [47]. These included:

1) Purpose of the literature review: The authors sought to identify relevant themes in the stream of research centered on the drivers, benefits, barriers, and challenges to organizational IoT adoption.

2) Protocol and training: A focused, systematic literature search was undertaken to identify all drivers, benefits, barriers, and challenges to organizational IoT adoption. Analysis of the identified literature was supported through the development of a concept matrix [76], which provided a simple, visual diagrammatic representation of the key determinants identified and their frequency, categorized according to the four UTAUT constructs.

3) Searching for the literature: The requirement for an article to be considered for analysis was the presence of the following terms within the paper title, abstract, or keywords: 'Internet of Things OR IoT' AND 'adoption OR drivers OR benefits OR barriers OR challenges'. The literature collection sources were focused on the Association of Information Systems "Basket of 8" and the "Business Source Complete" bibliographic collection, and sought to identify scholarly peer reviewed articles published 2010 and 2017 included. The authors identified 253 papers.

4) Practical screen: Resulting from this step was a list of the literature to be considered for review. An initial screen of the title, abstract, and keywords of the 253 identified papers resulted in the exclusion of 207 papers due, for example, to language or a focus on issues that did not illuminate specific adoption determinants. All remaining papers were read to verify their relevance. In parallel, analysis of the references of those initially selected papers was also undertaken. Consequently, 46 papers were systematically ordered and selected to achieve the SLR's objective.

5) Quality appraisal: The 46 eligible papers were also evaluated in terms of quality. Given the search focus for scholarly peer reviewed articles, no quality-related issues were found.

6) Data extraction: Within each of the shortlisted papers the relevant material to answer the review question was isolated, and all drivers, benefits, barriers, and challenges to IoT adoption were extracted. Hence, this step provided a list of all relevant concepts to synthesize the study.

7) Synthesis of studies: A content analysis of the material extracted from the literature was undertaken to establish the most common concepts. The authors created a high-level categorization comprising the four constructs of UTAUT, according to which the drivers, benefits, barriers, and challenges were classified based on their fit according to the UTAUT constructs (Table 1). The authors followed the concept matrix 
method [76] - the matrix rows provide the paper references from which the concepts were extracted, while frequency of occurrence of a particular theme is indicated by the number of ' $\mathrm{Xs}$ ' in the table columns.

8) Writing the review: The final step involved a write up of the review. In the next section, the identified determinants are described based on their categorization within the UTAUT constructs.

\section{SLR: Key Findings from the Literature}

This section provides the key literature findings in relation to organizational IoT adoption that were identified through the SLR. These are discussed separately below for each of the UTAUT constructs.

Performance Expectancy: As outlined in Table 1, six of the twelve determinants identified were found to be related to Performance Expectancy. These primarily emerged as the expected benefits and usefulness of IoT for organizations. A description and discussion of each item is providedbelow.

Improved integration and connectivity potential: With the advent of IoT, networked connections have become more valuable. Through technologies embedded in sensor and actuator networks, IoT has the potential to enable the constant and ubiquitous connectivity of different devices [14, 22]. A key development trend is that of IoT's integration with existing network systems [79] and support for inter-organizational integration [24].

Real-time data visibility and sharing: IoT is one of the key sources of big data [12]. The connectivity of IoT devices enables the dynamic generation of vast volumes of real-time or near real- time granular intelligence data [45, 63]. The practice of ongoing sensing increases data richness to include details such as the status of items or their surroundings, and gives rise to more "trusted" data that is difficult to influence due to its continuous collection [26]. Sharing of this data across interconnected devices improves situational awareness and provides opportunities for smarter services [40] including connected marketing, and reality-augmented customer services $[14,40]$.

Improved business analytics and decision-making: The embedding of business analytic tools in IoT devices enables dynamic drill down, querying, and analysis of intelligence data [10, 52], diagnostics and complex problem-solving [46, 54], and enables real-time decision-making to take place at the data source [63, 77]. This often occurs autonomously without human intervention [14]. The analytics enabled by IoT technologies provide actionable insights on the organization's strengths and weaknesses [24], and enables it to react to events promptly [53]. 


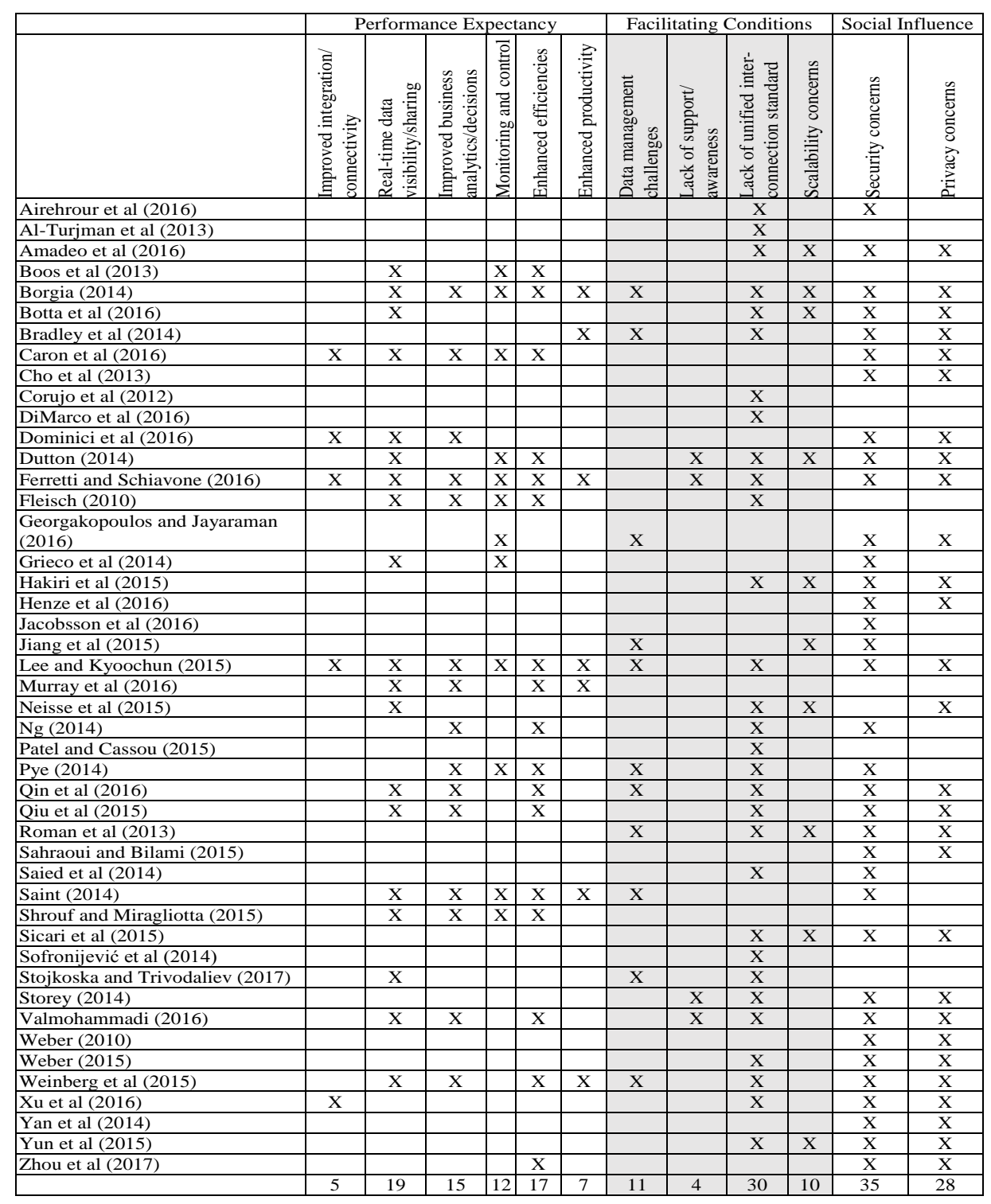

Table. 1. Concept matrix of IoT adoption drivers, benefits, barriers, challenges. 
Monitoring and control: IoT-enabled data availability facilitates real or near realtime performance monitoring and tracking (e.g. of entire product lifecycles, supply chain status, equipment performance, energy consumption) [14, 63]. Organizations can leverage the benefits of remote control capabilities $[22,77]$ to, for example, enable timely reaction to critical parameter measurements [28] and implement simple preventative maintenance concepts [52].

Enhanced organizational efficiencies: Operating efficiencies enabled by IoT can result from improved systems and procedures [40], such as the use of proximity or sensor triggers that can automatically initiate an activity [26]. IoT-enabled redesign and streamlining or automation of business processes can minimize the intervention required by humans [26] or improve coordination between people, products, and procedures [24], and result in greater business agility [52, 77], and procedural innovation [43]. Operating efficiencies can materialize in the form of improved transaction speed and accuracy [43], reduced labor, transaction, and process failure costs [24, 53], reduced waste [10, 23], improved energy efficiency [77], and supply chain responsiveness [71].

Enhanced organizational productivity: Through the effective coordination of IoT devices, systems can be harnessed to increase organizational productivity [13, 61]. This includes, for example, improved value chain productivity across product design, inventory management, manufacturing, logistics, and customer service [22, 43, 77]. Similarly, employee productivity can be enhanced, with the organization leveraging its employees' skills to their full potential [24, 40], and over time increasing the value of intellectual capital [43].

Facilitating Conditions: With respect to Facilitating Conditions, four determinants were identified from the literature (Table 1). Of these, lack of organizational support and awareness refers to the availability of a specific person or group "for assistance with system difficulties" as defined as part of the original construct [73, p. 460]. The remaining four relate to internal and external constraints encompassing resource facilitating conditions and technology facilitating conditions [3, 68, 73].

Lack of a unified interconnection standard: A unified, global interconnection standard to support seamless integration across IoT devices does not exist [67, 71]. This gives rise to the implementation complexities of fragmented solutions and interoperability challenges for organizations [6, 81], and closed IoT ecosystems [23, 81], thereby reducing the value proposition for IoT investment [46, 71]. Several standardization issues exist including those pertaining to data format, data interfaces, protocols, service platform, and architecture [10]. Establishing a universal standard is challenged by the number of organizations and industry bodies with a vested interest in the IoT ecosystem [67]. The potential exists for large vendors to frustrate the path to standardization by developing closed proprietary IoT solutions around their own products [13]. 
Scalability concerns: The exponential growth of big data generated by connected IoT devices gives rise to considerable scalability and extensibility challenges [7], increasing scalability requirements many orders of magnitude higher than currently available on the Internet [23]. Confidence in the availability of a scalable, cost efficient architecture to address the complexities of the IoT 'data deluge' is important in ensuring faster uptake of IoT [10].

Data management challenges: Estimates suggest that IoT data generation will grow from a present volume of 4 zettabytes to over 40 zettabytes in 2020 [77]. This large-scale data is characterized by issues such as velocity, quality, redundancy, inconsistency, incompleteness, and ambiguity [38, 53]. However, current data center architecture is inadequate to cater for both the data volumes and its heterogeneous nature [40]. In a reversal of trends, IoT is driving the need for distributed data center management to improve data processing efficiency and response time [13]. To support effective organizational adoption, new algorithms and technologies are required for data processing and storage [77]. Efficient representation schemes and indexing methods are required to readily locate specific data items [10], as well as sophisticated data mining tools to make sense of the data [61].

Lack of organizational support and awareness: IoT adoption in organizations is impacted by a lack of senior management knowledge, commitment, and support, inadequate employee technological skills [24, 71], and inadequate awareness of security and data privacy concerns [67]. Putting the organizational and institutional infrastructures in place to address the above is difficult due to the required social change, and potential resistance to changes in day-to-day work practices [23].

Social Influence: Significant emphasis was found in the literature regarding the role of Normative Pressure in influencing IoT adoption. In particular, this emerged as concerns pertaining to privacy and security, both of which are currently challenging the complete implementation of IoT systems.

Security concerns: IoT-specific security threats result from the proliferation of embedded and connected devices and underlying network heterogeneity [59, 79]. Security attacks include, for example, identity fabrication, unauthorized access to intellectual property, sabotage of critical infrastructure, and denial of service [31]. The implications of IoT specific security threats are often profound, offering cyber criminals the opportunity to take control of physical devices in close proximity to individuals [77]. Research highlights that there are several vulnerabilities inherent in IoT devices such as insecure web interfaces, software and firmware vulnerabilities, privacy issues, and lack of transport encryption and authentication/authorization [2, 40]. Several vulnerabilities are also created by human actors in an IoT system, including disgruntled employees [37].

Privacy concerns: The ubiquity of IoT devices gives rise to significant privacy concerns, including for example, the challenge of uncontrolled data generation and 
diffusion, inadequate authentication, preservation of anonymity, and risks pertaining to sensitive data [14, 33]. Akin to the concept of Orwellian surveillance, an issue of considerable importance is unauthorized surveillance that results in large-scale data collection without an individual's consent, leading to individual tracking and behavior inference [75]. Data ownership is also a concern [22], with questions arising in terms of who owns the data in a system where multiple actors co-create and add value [77]. Privacy concerns are exacerbated when data is outsourced to the cloud, as a result of data transfer, storage, and processing across legislative boundaries, and perceived loss of control with regards to data access by third parties [33].

Effort Expectancy: As outlined in Table 1, none of the IoT adoption determinants uncovered through the SLR were found to be related to Effort Expectancy. Given that this construct is concerned with the degree of effort required in using a new technology, the authors argue that this may be an area currently overlooked in IoT adoption literature, particularly given the differences and complexities associated with IoT compared to other technologies. In the next research phase, it is anticipated that aspects such as required "learning to operate the system" [19, 56, 73] will emerge as empirical data is gathered from organizations that have adopted IoT.

\section{$5 \quad$ Conclusions and Future Research}

This IoT adoption is different from that of other technologies in that it reflects adoption of a complex "sys- tem of systems", comprised of multiple hardware, software, and networking technologies that are often faced with fragmentation and interoperability challenges. To date, it is poorly understood by the IS research community. A paucity of studies in this area is evident, as of the papers systematically reviewed throughout this study's SLR process, none of those pertaining to IoT adoption determinants were published in journals of the AIS "basket of eight". This paper, proposes an initial contribution to the IS challenge outlined in the forthcoming Special Issue of the Journal of Strategic Information Systems on the need to understand "How will theories of IT adoption and diffusion develop to take account of the IoT?” The findings of this research serve three purposes. Firstly, the paper elucidates the current understanding in the extant literature on the determinants for organizational adoption of IoT through undertaking a SLR. It highlights that adoption may be influenced by the fact that IoT can improve integration and connectivity, real-time data visibility, business analytics and decision-making, to provide improved organizational efficiencies and productivity. However, the decision to adopt may also be influenced by a number of constraints, such as lack of a unified interconnection standard, lack of internal awareness and support, coupled with concerns around scalability, security, privacy, and data management. Secondly, by categorizing these determinants according to the four UTAUT constructs, the 
paper provides initial insights on the applicability of UTAUT in explaining organizational IoT adoption. In its current formulation, UTAUT appears a viable option for investigating IoT. All of the determinants identified through the SLR could be explained by the Performance Expectancy, Social Influence, and Facilitating Conditions constructs of UTAUT. Interestingly, we did not uncover any determinants that could not be explained by the existing UTAUT constructs, which provides further support for its relevance in relation to explaining adoption of emerging and complex systems of technologies. Thirdly, Effort Expectancy did not underpin any determinant identified in the current literature. We believe this represents an important gap and a research opportunity for IS scholars. Important questions in this way remain substantially unanswered in the IS literature to date. For example: what is the learning curve to effectively adopt and make full use of IoT? What skills are needed at the individual and organizational level to effectively adopt and use IoT? The work presented in this paper will also serve as the basis for an empirical investigation in the next phase of this study. A quantitative research approach, in the form of an online survey [8], will be employed to gain greater insights into this phenomenon, and to further investigate the relevance of the determinants across different contexts. The survey will target individuals holding CIO, CTO, or equivalent roles in organizations, as those individuals are regarded as most likely to have the greatest knowledge of the organization's IoT adoption efforts. The insights gleaned from the data will produce an empirically validated model that outlines the key determinants influencing IoT adoption in an organizational setting. The contribution from this research will address the current paucity of studies, and thereby from a practical perspective, enable an organization to make more informed decisions regarding IoT adoption and use, and provide IoT solution providers with greater insights into the key determinants to organizational adoption of IoT. From a theoretical perspective, insights gained from the theoretical framework will enable a formal enrichment/extension to UTAUT that contextualizes its constructs to IoT adoption determinants.

\section{References}

1. Accenture. (2015). "From Productivity to Outcomes. Using the Internet of Things to Drive Future Business Strategies,” Accenture.

2. Airehrour, D., Gutierrez, J., and Ray, S. (2016). "Secure Routing for Internet of Things: a Survey,” Journal of Network and Computer Applications 66, 198-213.

3. Ajzen, I., (1991). "The Theory of Planned Behavior," Organizational Behavior and Human Decision Processes 50 (2), 179-211.

4. Al Awadhi, S., and Morris, A. (2008). "The Use of the UTAUT Model in the Adoption of e- Government Services in Kuwait,” in Proceedings of the 41st Hawaii International Conference on System Sciences, IEEE, Hawaii, 1-11. 
5. Al-Harby, F., Qahwaji, R., and Kamala, M. (2010). "Users’ Acceptance of Secure Biometrics Authentication System: Reliability and Validation of an Extended UTAUT Model," Communications in Computer and Information Science 87 (2), 254-258.

6. Al-Turjman, F., Al-Fagih, A., Alsalih, W., and Hassanein, H. (2013). “A Delay-Tolerant Framework for Integrated RSNs in IoT,” Computer Communications 36, 998-1010.

7. Amadeo, M., Campolo, C., Quevedo, J., Corujo, D., Molinaro, A., Lera, A., Aguiar, R., and Vasilakos, (2016). "Information-Centric Networking for the Internet of Things: Challenges and Opportunities,” IEEE Network (March/April), 92-100.

8. Blumberg, B., Cooper, D.R., and Schlinder, P.S. (2014). Business Research Methods, Berkshire, UK: McGraw Hill.

9. Boos, D., Guenter, H., Grote, G., and Kinder, K. (2013). "Controllable Accountabilities: the Internet of Things and its Challenges for Organizations," Behaviour \& Information Technology 32 (5), 449-467.

10. Borgia, E. (2014).“The Internet of Things Vision: Key Features, Applications and Open Issues,” Computer Communications 54, 1-31.

11. Bosche, A., Crawford, D., Jackson, D., Schallehn, M., and Smith, P. (2016). "How Providers can Succeed in the Internet of Things”. Bain Insights.

12. Botta, A., de Donato, W., Persico, V., Pescape, A. (2016). "Integration of Cloud Computing and Internet of Things: a Survey,” Future Generation Computer Systems 56, 684-700.

13. Bradley, T., Thibodeau, P., and Ng, V. (2014). "The Internet of Things - Threats and Challenges,” Network World Asia (March/April), 16-18.

14. Caron, X., Bosua, R., Maynard, S., and Ahmad, A. (2016). "The Internet of Things (IoT) and its Impact on Individual Privacy: An Australian Perspective,” Computer Law \& Security Review 32, 4- 15.

15. Chisolm, D.J., Purnell, T.S., Cohen, D.M., and McAlearney, A.S. (2010). “Clinician Perceptions of an Electronic Medical Record during the First Year of Implementation in Emergency Services,” Pediatric Emergency Care 26 (2), 107-110.

16. Cho, K., Lee, B., Lee, K., Lee, D. (2013). "Energy-efficient Replica Detection for Resourcelimited Mobile Devices in the Internet of Things,” IET Communications 7 (18), 2141-2150.

17. Compeau, D.R. and Higgins, C.A. (1995). "Computer Self-efficacy: Development of a Measure and Initial Test,” MIS Quarterly 19 (2), 189-211.

18. Corujo, D., Lebre, M., Gomes, D., and Aguiar, R. (2012). "MINDiT: A Framework for Media Independent Access to Things," Computer Communications 35, 1772-1785.

19. Davis, F.D. (1989). "Perceived Usefulness, Perceived Ease of Use, and User Acceptance of Information Technology,” MIS Quarterly 13 (3), 319-340.

20. Davis, F.D., Bagozzi, R.P., Warshaw, P.R. (1992). "Extrinsic and Intrinsic Motivation to use Computers in the Workplace,” Journal of Applied Social Psychology 22(14), 1111-1132.

21. DiMarco, P., Athanasiou, G., Mekikis, P., and Fischione, C. (2016). "MAC-aware Routing Metrics for the Internet of Things,” Computer Communications 74, 77-86.

22. Dominici, G., Roblek, V., Abbate, T., and Tani, M. (2016). "Click and Drive,” Business Process Management Journal 22 (2), 420-434.

23. Dutton, W. (2014). "Putting Things to Work: Social and Policy Challenges for the Internet of Things,” Info 16 (3), 1-21. 
24. Ferretti, M., Schiavone, S. (2016). "Internet of Things and Business Processes Redesign in Sea- ports: the Case of Hamburg,” Business Process Management Journal 22 (2), 271-284.

25. Fishbein, M., and Ajzen, I. (1975). Belief, Attitude, Intention and Behavior: an Introduction to Theory and Research. Massachusetts: Addison-Wiley Publishing Company.

26. Fleisch, E. (2010). "What is the Internet of Things?: an Economic Perspective,” Economics, Management, and Financial Markets 5 (2), 125-157.

27. Georgakopoulos, D., and Jayaraman, P.P. (2016). "Internet of Things: from Internet Scale Sensing to Smart Services," Computing 98 (10), 1041-1058.

28. Grieco, L., Rizzo, A., Colucci, S., Sicari, S., Piro, G., Di Paola, D., and Boggia, G. (2014). "IoT-aided Robotics Applications: Technological Implications, Target Domains and Open Issues," Computer Communications 54, 32-47.

29. Guo, B., Zhang, D., Wang, Z., Yu, Z., and Zhou, X. (2013). "Opportunistic IoT: Exploring the Harmonious Interaction between Humans and the Internet of Things,” Journal of Network and Com- puter Applications 36, 1531-1539.

30. Haass, R., Dittmer, P., Veigt, M., and Lütjen, M. (2015). "Reducing Food Losses and Carbon Emission by using Autonomous Control-A Simulation Study of the Intelligent Container”. International Journal of Production Economics 164, 400-408.

31. Hakiri, A., Berthou, P., Gokhale, A., and Abdellatif, S. (2015). "Publish/Subscribe-enabled Software Defined Networking for Efficient and Scalable IoT Communications,” IEEE Communications Magazine 53 (9), 48-54.

32. Heikkila, J., Smale, A. (2010). "The Effects of Language Standardization on the Acceptance and Use of e-HRM Systems in Foreign Subsidiaries,” Journal of World Business 46(3),1-9.

33. Henze, M., Hermerschmidt, L., Kerpen, D., Häußling, R., Rumpe, B., and Wehrle, K. (2016). "A Comprehensive Approach to Privacy in the Cloud-based Internet of Things," Future Generation Computer Systems 56, 701-718.

34. Hu, P.J., Chau, P.Y., Sheng, O.R.L., and Tam, K.Y. (1999). "Examining the Technology Acceptance Model using Physician Acceptance of Telemedicine Technology,” Journal of Management Information Systems 16 (2), 91-112.

35. Huang, S., and Wang, X. (2009). "Influence of Organizational System to End-users' Acceptance of ERP System in Chinese Enterprises”, in Proceedings of the 9th International Conference on Hybrid Intelligent Systems, IEEE, Shenyang, China, 160-164.

36. Intel, (2017). "The Intel IoT Platform - Architecture Specification White Paper," URL: https://www.intel.com/content/dam/www/public/us/en/documents/white-papers/iot-platform- reference-architecture-paper.pdf.

37. Jacobsson, A., Boldt, M., and Carlsson, B. (2016). "A Risk Analysis of a Smart Home Automation System,” Future Generation Computer Systems 56, 719-733.

38. Jiang, H., Shen, F., Chen, S., Li, K., and Jeong, Y. (2015). “A Secure and Scalable Storage System for Aggregate Data in IoT,” Future Generation Computer Systems 49, 133-141.

39. Lang, W., Jedermann, R., Mrugala, D., Jabbari, A., Krieg-Brückner, B. and Schill, K. (2011). "The "Intelligent Container"—a Cognitive Sensor Network for Transport Management”. IEEE Sensors Journal 11 (3), 688-698.

40. Lee, I., and Kyoochun, L. (2015). "The Internet of Things (IoT): Applications, Investments, and Challenges for Enterprises,” Business Horizons 58, 431—440. 
41. McKinsey. (2015). "The Internet of Things: Mapping the Value Beyond the Hype".

42. Mishra, D., Gunasekaran, A., Childe, S.J., Papadopoulos, T., Dubey, R., Wamba, S. (2016). "Vision, Applications and Future Challenges of Internet of Things: A Bibliometric Study of the Re- cent Literature”. Industrial Management \& Data Systems 116 (7), 1331-1355.

43. Murray, A., Papa, A., Cuozzo, B., and Russo, G. (2016). "Evaluating the Innovation of the Internet of Things,” Business Process Management Journal 22 (2), 341-356.

44. Nakicenovic, N., and Grübler, A. (eds.), (2013). Diffusion of Technologies and Social Behavior, Berlin, Germany: Springer Science \& Business Media.

45. Neisse, R., Steri, G., Fovino, I., and Baldini, G. (2015). "SecKit: A Model-based Security Toolkit for the Internet of Things," Computers and Security 54, 60-76.

46. Ng, V. (2014). "Drivers and Obstacles to IoT Adoption in Asia Pacific," Network World Asia (September/October), 12-14.

47. Okoli, C. (2015). “A Guide to Conducting a Standalone Systematic Literature Review," Communication of the Association for Information Systems 37 (43), 879-910.

48. Pai, J.C., and Tu, F.M. (2011). "The Acceptance and Use of Customer Relationship Management (CRM) Systems: an Empirical Study of Distribution Service Industry in Taiwan”, Expert Systems with Applications 38 (1), 579-584.

49. Papert, M., Pflaum, A. (2017) "Development of an Ecosystem Model for the Realization of Internet of Things Services in Supply Chain Management” Electronic Markets 27(2),175.

50. Paré, G., Trudel, M.C., Jaana, M., Kitsiou, S. (2015). "Synthesizing Information Systems Knowledge: A Typology of Literature Reviews,” Information \& Management 52 (2), 183.

51. Patel, P., and Cassou, D. (2015). "Enabling High-level Application Development for the Internet of Things," The Journal of Systems and Software 103, 62-84.

52. Pye, A. (2014). "The Internet of Things: Connecting the Unconnected," Engineering and Technology (December), 64-70.

53. Qin, Y., Sheng, Q., Falkner, N., Dustdar S., Wang, H., and Vasilakos, A. (2016). "When Things Matter: a Survey on Data-centric Internet of Things,” Journal of Network and Computer Applications 64, 137-153.

54. Qiu, X., Luo, H., Xu, G., Zhong, R., and Huang, G. (2015). "Physical Assets and Service Sharing for IoT-enabled Supply Hub in Industrial Park (SHIP),” International Journal of Production Economics 159, 4-15.

55. Rogers, E.M. (1995). Diffusion of Innovations, New York: Free Press.

56. Rogers, E.M., (2010). Diffusion of Innovations, New York: Simon and Schuster.

57. Roman, R., Zhou, J., and Lopez, J. (2013). "On the Features and Challenges of Security and Privacy in Distributed Internet of Things,” Computer Networks 57, 2266-2279.

58. Rowe, F. (2014). "What Literature Review is Not: Diversity, Boundaries and Recommendations,” European Journal of Information Systems 23 (3), 241-255.

59. Sahraoui, S., and Bilami, A. (2015). "Efficient HIP-based Approach to Ensure Light Weight End-to- end Security in the Internet of Things," Computer Networks 91, $26-45$.

60. Saied, Y., Olivereau, A., Zeghlache, D., and Laurent, M. (2014). "Lightweight Collaborative Key Establishment Scheme for the Internet of Things,” Computer Networks 64, 273-295.

61. Saint, A. (2014). "Internet of Things: Brave New World,” Engineering and Technology, 80. 
62. Sambasivan, M., Wemyss, G.P., and Rose, R.C. (2010). "User Acceptance of a G2B System: a Case of Electronic Procurement System in Malaysia,” Internet Research 20 (2), 169-187.

63. Shrouf, F., and Miragliotta, G. (2015). "Energy Management Based on Internet of Things: Practices and Framework for Adoption in Production Management," Journal of Cleaner Production 100, 235-246.

64. Sicari, S., Rizzardi, A., Grieco, L., and Coen-Porisini, A. (2015). "Security, Privacy and Trust in Internet of Things: The Road Ahead,” Computer Networks 76, 146-164.

65. Sofronijević, A., Milićević, V., and llić, B. (2014). "Smart City as a Framework for Creating Competitive Advantages in International Business Management,” Management 71, 5-15.

66. Stojkoska, B.L.R., and Trivodaliev, K.V. (2017). "A Review of Internet of Things for Smart Home: Challenges and Solutions,” Journal of Cleaner Production 140, 1454-1464.

67. Storey, A. (2014). “There’s Nothing ‘Smart’ About Insecure Connected Devices,” Network Security 7, 9-12.

68. Taylor, S., and Todd, P.A. (1995). "Understanding Information Technology Usage: A Test of Competing Models,” Information Systems Research 6 (2), 144-176.

69. TEKSystems. (2016). "The State of the Internet of Things: Executive Summary".

70. Thompson, R.L., Higgins, C.A., and Howell, J.M. (1991). "Personal Computing: Toward a Conceptual Model of Utilization,” MIS Quarterly 15 (1), 124-143.

71. Valmohammadi. C. (2016). "Examining the Perception of Iranian Organizations on Internet of Things Solutions and Applications,” Industrial and Commercial Training 48 (2), 104-108.

72. Venkatesh, V., and Davis, F.D. (2000). "A Theoretical Extension of the Technology Acceptance Mod- el: Four Longitudinal Field Studies,” Management Science 46 (2), 186-204.

73. Venkatesh, V., Morris, M.G., Davis, G.B., and Davis, F.D. (2003). "User Acceptance of Information Technology: Toward a Unified View,” MIS Quarterly 27 (3), 425-478.

74. Weber, R. (2010). "Internet of Things - New Security and Privacy Challenges," Computer Law and Security Review 26, 23-30.

75. Weber, R. (2015). “Internet of Things: Privacy Issues Revisited,” Computer Law and Security Review 31, 618-627.

76. Webster, J. and Watson, R.T. (2002). “Analyzing the Past to Prepare for the Future: Writing a Literature Review,” MIS Quarterly 26 (2), 13-23.

77. Weinberg, B., Milne, G., Andonova, Y., and Hajjat, F. (2015). "Internet of Things: Convenience vs. Privacy and Secrecy,” Business Horizons 58, 615-624.

78. Williams, M.D., Rana, N.P., and Dwivedi, Y.K. (2015). “The Unified Theory of Acceptance and Use of Technology (UTAUT): a Literature Review,” Journal of Enterprise Information Management 28 (3), 443-488.

79. Xu, K., Qu, Y., and Yang, K. (2016). “A Tutorial on the Internet of Things: From a Heterogeneous Network Integration Perspective,” IEEE Network (March/April), 102-108.

80. Yan, Z., Zhang, P., and Vasilakos, A. (2014). "A Survey on Trust Management for Internet of Things,” Journal of Network and Computer Applications 42, 120-134.

81. Yun, J., Ahn, I., Sung, N., Kim, J. (2015). “A Device Software Platform for Consumer Electronics Based on the Internet of Things,” IEEE Transactions on Consumer Electronics 61(4).

82. Zhou, J., Cao, Z., Dong, X., and Vasilakos, A.V. (2017). "Security and Privacy for CloudBased IoT: Challenges,” IEEE Communications Magazine 55 (1), 26-33. 